\title{
TROCAS SOCIODIALETAIS ENTRE FALANTES TOPOESTÁTICOS E TOPODINÂMICOS: DADOS DO ALITTETO
}

\section{SOCIAL-DIALECTICAL EXCHANGES BETWEEN TOPOSTATIC AND TOPODYNAMIC SPEAKERS. ALITTETO DATA}

\author{
Greize Alves da Silva \\ Universidade Federal de Tocantins, Palmas, Tocantins, Brasil \\ Vanderci de Andrade Aguilera \\ Universidade Estadual de Londrina, Londrina, Paraná, Brasil
}

\begin{abstract}
Resumo: Nas últimas décadas, o Brasil tem vivenciado um processo de grande mobilidade sociogeográfica, o que se traduz em uma nova configuração linguística, decorrente do contato entre diferentes modalidades dialetais no mesmo espaço. Estudos mais recentes em Sociolinguística e em Dialetologia têm atestado que fatores sócio-históricos e sócioeconômicos decorrentes da mobilidade da população acarretam, por vezes, a transformação de cenário dentro dos estudos que visam averiguar os processos de variação e de mudança linguística. Nesse panorama, este texto objetiva demonstrar o comportamento linguístico, sobretudo na área do léxico, de informantes topodinâmicos, moradores atuais do Tocantins, em comparação com informantes topoestáticos naturais das doze localidades investigadas para o Atlas Linguístico Topodinâmico e Topoestático do Estado do Tocantins (ALiTTETO).
\end{abstract}

Palavras-chave: Atlas Linguístico; Dialetologia Pluridimensional; Diatópico-cinético; Variação Lexical; Tocantins

Abstract: During the last decades, Brazil has been experiencing a process of great sociogeographic mobility, with subsequent linguistic configurations caused by contacts between different dialectic modalities within the same space. Recent studies in Sociolinguistics and in Dialectology revealed that socio-historical and socio-economic factors due to population mobility have often transformed the scenario within the studies that aim at verifying the processes of linguistic variation and change. Current paper shows, especially within the lexical area, the linguistic behavior of topodynamic informants, currently living in the state of Tocantins, Brazil, compared to topostatic ones who are native of twelve localities investigated in the Topodynamic and Topostatistic Linguistic Atlas of the State of Tocantins (ALiTTETO).

Keywords: Linguistic Atlas; Pluridimensional Dialectology; Diatopic-kinetic; Lexical Variation; Tocantins 


\section{INTRODUÇÃO}

A mobilidade espacial tem sido, ao longo da história, uma característica intrínseca da maioria da população brasileira. No entanto, nas últimas décadas, sobretudo entre 1970-2000, conforme ilustra Simielli (2006, p.121), constata-se uma intensificação desse movimento, em decorrência de vários fatores, dentre os quais se destacam: a) distâncias geográficas em um país com vasta extensão territorial; b) concentração de riquezas em algumas áreas, como as Regiões Sul e Sudeste, em detrimentos de outras, como a Norte e a Nordeste; c) expansão das atividades agropastoris e mineradoras para o Centro-Oeste e Norte, atraindo migrantes sulistas e sudestinos incentivados por programas do governo federal, com vistas à ocupação da área da Amazônia e do Oeste do Brasil.

Embora, com maior frequência, ocorra o fato de populações mais carentes se deslocarem para outros estados em busca de melhores oportunidades, verifica-se que grupos econômicos consolidados, como pecuaristas e fazendeiros, buscam também outras áreas para ampliar seus latifúndios.

Em termos linguísticos, por vezes, pesquisadores têm atestado um processo intitulado "desenraizamento linguístico" (PENNA, 2006), uma vez que esse contato entre migrante e autóctone nem sempre é passivo, fazendo com que o primeiro, eventualmente, perca sua identidade dialetal, sobretudo quando suas raízes são procedentes de estratos sociais mais baixos.

Por outro lado, quando os migrantes se deparam nesse novo ambiente com a possibilidade de melhores condições de sobrevivência e de melhora significativa em sua situação socioeconômica, o falante pode apresentar atitudes positivas em relação ao falar local (SILVA, 2018) e considerar as diferenças sociodialetais com um olhar menos carregado de estigma.

$\mathrm{Na}$ perspectiva dialetológica, a partir desse mosaico contrastivo entre diferentes modalidades da mesma língua, no caso do português, novos rumos foram necessários para essa descrição dos veios socioletais presentes em solo brasileiro. O informante sedentário, nascido e radicado na mesma região, alvo da preferência da Dialetologia tradicional, constitui-se uma exceção, atualmente, dada a dificuldade de uma pessoa permanecer a vida toda na mesma localidade em que nasceu (ALTENHOFEN; THUN, 2016). Nesse sentido, são importantes as contribuições oriundas da Dialetologia Pluridimensional e Relacional, a partir dos aspectos contrastivos entre diferentes grupos de informantes: os migrantes e os autóctones que dividem o mesmo espaço geográfico onde ocorre a pesquisa.

Nesse entendimento dos fatores de mobilidade brasileira, intencionou-se, a partir da seleção de dados coletados pelo ALiTTETO - Atlas Linguístico Topodinâmico e Topoestático do Estado do Tocantins (SILVA, 2018), averiguar o comportamento dialetal dos falantes que vivem no Estado do Tocantins, constituído o mais novo da federação brasileira e formado sob a égide dos processos de migração e transmigrações (ALTENHOFEN; THUN, 2016, p. 387).

Do contraste entre informantes nascidos e estabelecidos nas cidades pesquisadas e os de procedência extralocalidade, buscou-se responder à questão: Identificadas as modalidades dialetais, oriundas dos dois diferentes grupos, topoestáticos e topodinâmicos, quais relações elas exercem: de covariação ou de exclusão mútua? (SILVA, 2018).

Em outras palavras, intenciona-se verificar se os informantes extralocalidades adaptam seu falar à realidade local ou possuem uma atitude mais centrífuga, desviando-se da variante mais local e retomando a variante de origem natal, de seu ponto de partida. 


\section{PRESSUPOSTOS TEÓRICOS}

A perspectiva adotada pela Dialetologia Pluridimensional e Relacional parte do princípio de que se podem averiguar, no mesmo espaço geográfico, os vários ângulos da variação, aliando as vertentes sociais fornecidas pela Sociolinguística à vertente areal (viés diatópico) focalizada pela Dialetologia e pela Geografia Linguística, conforme se observa no esquema representado na Figura 01.

Figura 01: Princípio esquemático da Dialetologia Pluridimensional e Relacional

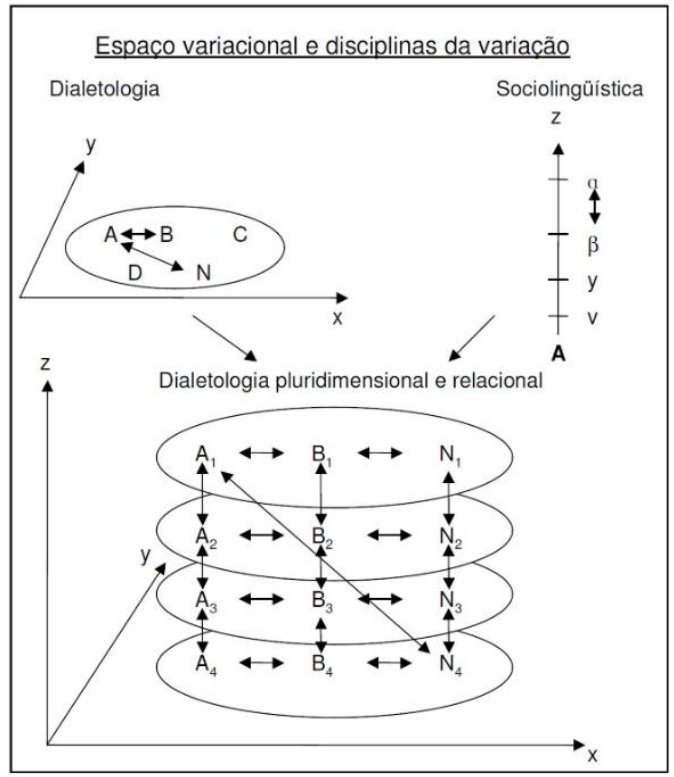

Fonte: Thun (1998, p. 705)

Verifica-se, na Figura 01, que o esquema disposto no alto, à esquerda, demonstra que os inquéritos linguísticos utilizados pela Dialetologia tradicional estão circunscritos à mesma realidade linguística, cuja análise posterior dos dados detém-se nas diferenças presentes apenas no plano diatópico, distinção entre as letras maísculas A, B, C..., ou seja, os pontos de inquérito. Nesse caso, para os veios sociais: se o informante do ponto A é do sexo feminino e se enquadra em uma categoria etária mais conservadora, entre outros, o plano contrastivo diatópico (entre ponto $\mathrm{A}$ e ponto $\mathrm{B}$ ), não é ponto fundamental nesse princípio esquemático, mas interessam à Sociolinguística, em um plano estritamente vertical, as relações estabelecidas dentro dos estratos sociais, indicados à direita, onde se encontram os tipos de informantes nas várias distribuições hierárquicas. Nesse caso, os pontos de inquérito linguístico, alvos da Dialetologia, são pouco relevantes, uma vez que o enfoque está nos grupos sociais em que se inserem os informantes.

O esquema, que se encontra logo abaixo na Figura 01, representa o foco da Dialetologia Pluridimensional e Relacional (THUN, 1998, p. 705) na proposta de união entre o plano horizontal (Dialetologia) e o plano vertical (Sociolinguística). Assim, unem-se o intento diatópico com as variáveis sociais, em forma de camadas, que podem ser analisadas binariamente, levando o pesquisador a uma descrição completa do polimorfismo linguístico e da relação do informante com essa variação. A binaridade presente na proposta, em outras palavras, estabelece caráter diferenciador entre distintos estratos, por exemplo, entre faixa etária e sexo, permitindo estudos contrastivos.

Altenhofen (2013, p. 32) sinaliza que as variáveis sociais são entendidas dentro da vertente Pluridimensional como tipos de dimensões do plano variacionista, formando um conjunto de relações que podem ser opositivas, normalmente binárias, entre os parâmetros 
estabelecidos. Assim, ao analisar o contraste entre os registros dos informantes masculinos e femininos, entre falantes autóctones e alóctones à localidade, por exemplo, seria possível realizar uma completa descrição da variação linguística em determinada região, abrangendo múltiplas realidades, diferentemente do que se buscava na Dialetologia de base mais tradicional.

A importância da chamada dimensão diatópico-cinética, que contrasta variantes específicas de informantes estáticos com falantes demograficamente móveis, pauta-se, sobretudo, nos processos migratórios das últimas décadas, o que tem acarretado mudanças significativas na configuração dialetal dos brasileiros. Para Altenhofen e Thun (2016), falantes mais fixos à localidade possuem tendência mais conservadora, centrípeta, enquanto os informantes procedentes de migrações, os topodinâmicos, adotam uma postura mais inovadora ou sujeita à mudança linguística (centrífuga).

\subsection{O ESTADO DO TOCANTINS E O CONTEXTO MIGRATÓRIO INTER E INTRAESTADUAL}

O espaço tocantinense foi desmembrado de terras pertencentes ao Estado de Goiás em 1988, após alguns séculos de lutas travadas em prol da autonomia política da região intitulada "norte goiano". Os movimentos separatistas baseavam suas reivindicações nas diferenças econômicas e culturais entre a área mais setentrional de Goiás, hoje Tocantins, e a parte mais meridional, atual Goiás.

Em termos econômicos, a região norte goiana, em decorrência de seu distanciamento espacial de outras regiões brasileiras, tais como o Sul e o Sudeste, mais desenvolvidas em termos socioeconômicos, causou uma estagnação na economia da parte mais setentrional, principalmente após o declínio das minas auríferas, no século XIX, provocando o esvaziamento dos poucos núcleos populacionais e levando a população a dedicar-se às atividades de subsistência (SILVA, 2018).

Em termos culturais, em diferentes recortes temporais, o norte goiano contou com a presença indígena, africana e de mineiros em busca do ouro, fatores esses que fazem com que a cultura tocantinense seja descrita como híbrida, "resultado de associações étnicas e de universos culturais produzidos historicamente em contextos econômicos e conjunturas políticas diferenciados" (CAVALCANTE; KIMURA, 2008, p. 97).

As barreiras, tanto econômicas quanto culturais entre as duas populações: sul e norte goianas, são interpretadas por Teixeira Neto (1993 apud CAVALCANTE, 2003, p. 187) como determinantes na composição étnica e cultural do Tocantins, pois as levas migratórias provenientes dos estados das Regiões Norte e Nordeste, dadas as distâncias com o Centro-sul, assentaram-se no norte goiano.

Já os migrantes provenientes de São Paulo e de Minas Gerais fixavam-se no sul goiano, em função das dificuldades de acesso à região mais norte. Essa migração procedente de diferentes estados brasileiros deu origem a atividades econômicas diversificadas entre norte e sul goiano, pois:

[...] o Sul de Goiás muito mais próximo dos caminhos do Sul, e composto pelo Rio de Janeiro e Santos; e o Norte muito mais próximo e muito mais fácil o contato com o Pará que era o Porto de Belém. E esse interesse, é claro, criou mentalidades diferentes. E a atividade que mais caracterizou o Tocantins foi o comércio com o Pará e, depois, é claro, fazendas de gado trazido da Bahia, do Piauí, que se instalava ali nas margens do Tocantins justamente na margem direita, porque a margem direita era o lado povoado do Tocantins (TEIXEIRA NETO, 1993, apud CAVALCANTE, 2003, p. 188). 
Infelizmente, são precários os estudos estatísticos sobre as principais frentes migratórias, mas consta que, nos primórdios da povoamento do espaço do antigo estado de Goiás, o principal grupo migrante era composto por nordestinos, conforme indicado por Teixeira Neto (1993):

[...] eram famílias migrantes, vindas de regiões justamente problemáticas do Brasil, o Nordeste, sobretudo Maranhão, Piauí, e ali se criou uma mentalidade que era nortista, que se opunha em hábitos e costumes e até na maneira de encarar as diversidades, de enfrentar. É a rudeza do meio do Norte. O meio era muito mais rude, muito mais difícil, os deslocamentos muito mais penosos, não porque as barreiras fossem maiores que aqui, mas eram menos povoadas e a população tinha como unidade, como elemento de ligação entre elas, o rio Tocantins (TEIXEIRA NETO, 1993, apud CAVALCANTE, 2003, p. 189-190).

$\mathrm{O}$ rio Tocantins, citado pelo pesquisador, corta o território em sentido norte-sul, abriga as principais cidades históricas do atual Estado e muitas delas funcionaram como entrepostos comerciais, minas auríferas, etc. Atualmente, essas localidades possuem baixa densidade demográfica, uma vez que as populações dessas cidades têm buscado outras regiões mais desenvolvidas para viver.

A partir dos censos mais atuais, nota-se um aumento do contingente migratório procedente de outras regiões brasileiras, apesar do predomínio histórico de migrantes nordestinos, representados principalmente pelos maranhenses, conforme se verifica no Gráfico 1.

Gráfico 1: Percentual de grupos migrantes por Estados de origem - 1970 a 1996.

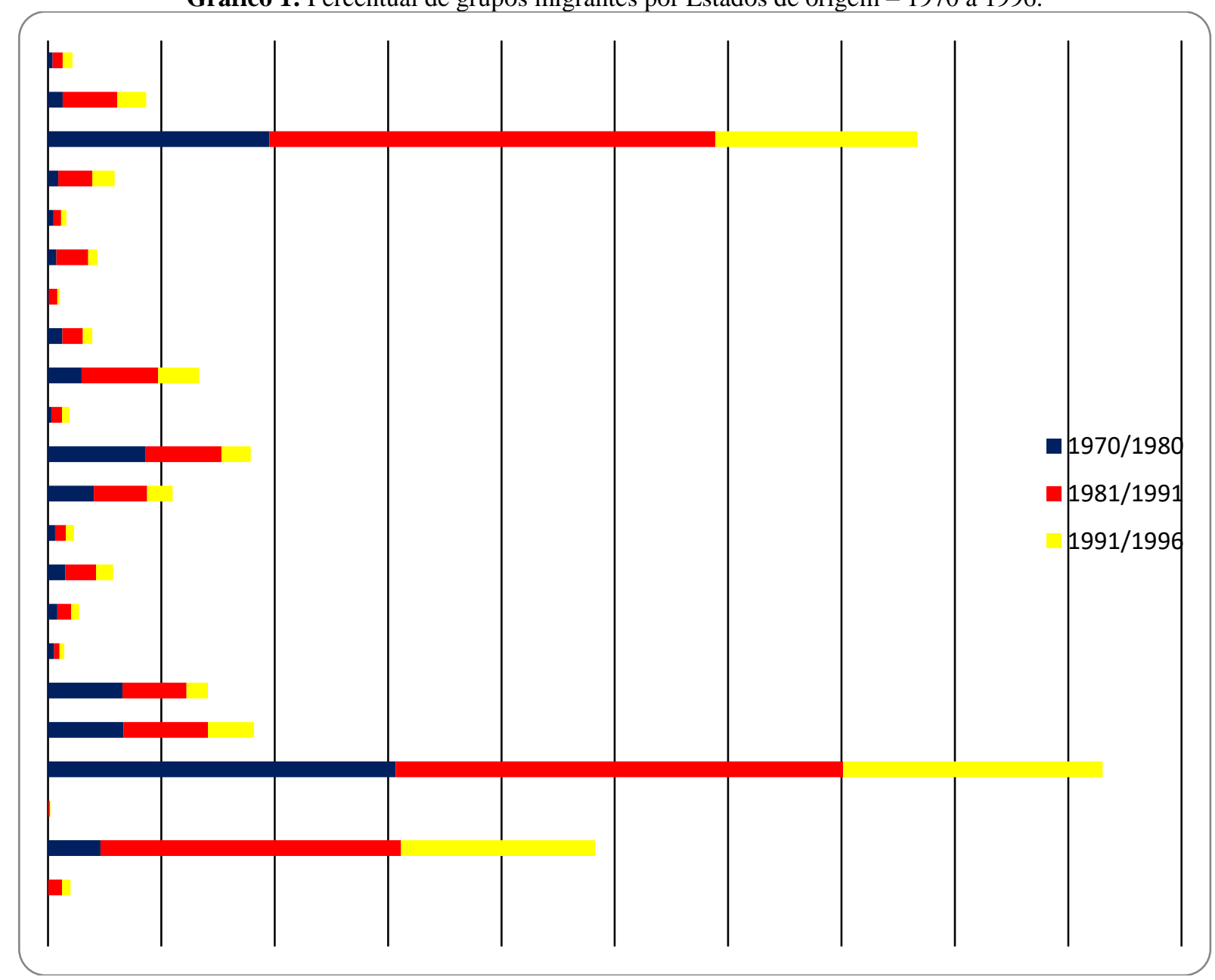

Fonte: Elaborado a partir de dados retirados de Cunha e Baeninger (2000, p. 06). 
Nos três recortes temporais (1970/1980; 1984/1991; 1991/1996), o migrante oriundo do Maranhão mostra-se como o tipo mais representativo no Tocantins, fato também atestado por Brasil (1997, p. 67): “O Tocantins contou com a forte influência da imigração proveniente do Nordeste, com 69\%, seguido do Sudeste, com 15\%. Com relação aos nordestinos, o fluxo mais importante foi oriundo (sic) do Maranhão, que correspondeu a 60\% do respectivo total".

Em segundo e terceiro lugares, Goiás e Pará, respectivamente, constituem outra parcela da população topodinâmica. Ou seja, os três grupos mais representativos (Maranhão, Goiás e Pará) são justamente os estados limítrofes ao espaço tocantinense. O Mato Grosso, apesar de fazer fronteira com a parte sudoeste do Estado, nesse recorte censitário não representa contingente migratório muito significativo.

\section{PERCURSO METODOLÓGICO}

O Atlas linguístico Topodinâmico e Topoestático do Estado do Tocantins (ALiTTETO) foi defendido como tese de doutorado, em 2018, vinculada ao Programa de Pós Graduação em Estudos da Linguagem, da Universidade Estadual de Londrina.

O respectivo trabalho seguiu os parâmetros propostos pela Dialetologia Pluridimensional e Relacional com o objetivo de descrever as realidades plurivarietais, principalmente as que apresentam forte contexto migratório, como o Estado do Tocantins.

Ao todo, selecionaram-se doze localidades, distribuídas pelas microrregiões tocantinenses: (01) Araguatins; (02) Tocantinópolis; (03) Araguaína; (04) Araguacema; (05) Palmas; (06) Pedro Afonso; (07) Porto Nacional; (08) Gurupi; (09) Mateiros; (10) Formoso do Araguaia; (11) Natividade e (12) Paranã.

Em cada localidade, inquiriu-se o total de oito informantes, distribuídos pelas variáveis faixa etária (i - 18 a 30; ii - 50 a 65 anos), sexo e tipo de mobilidade espacial. Nesse último parâmetro, entrevistaram-se os chamados informantes topoestáticos, ou seja, nascidos e estabelecidos nas localidades de pesquisa, e os topodinâmicos, informantes procedentes de migração estadual e/ou deslocamentos entre diferentes regiões, mas que moram nas cidades selecionadas há mais de 10 anos.

Aplicou-se um questionário linguístico semiestruturado, contendo, ao todo, 340 perguntas, distribuídas entre quatro subquestionários com vistas a averigiar os fatos fonéticofonológicos, semântico-lexicais, morfossintáticos e de crenças e atitudes linguísticas.

Este artigo descreve e analisa dados de natureza lexical, obtidos como respostas a duas perguntas selecionadas do Questionário Semântico-Lexical (QSL), e compara as variantes de acordo com os dois grupos de informantes: (i) topoestáticos e (ii) topodinâmicos. Apresentam-se, pois, os resultados obtidos por meio das perguntas relativas ao campo semântico "Frutas e Atividades Agropastoris": 025 - Como se chama a fruta que tem a casca verde, cheia de gominhos; abre-se com a mão e se chupa a semente",, e 028 - Como se chama a ponta roxa do cacho da banana?

No segundo momento, comparam-se os dados obtidos por meio da questão 028 , com os resultados da carta L07 do Atlas Linguístico do Brasil (CARDOSO et al, 2014, vol. 2).

Esse campo, especificamente, tem apresentado variantes mais conservadoras quando os referentes remetem às atividades rurais. Há que se considerar que falantes urbanos têm mais dificuldade para nomear um referente restrito às atividades agrícolas ou pastoris do que aqueles que habitam o campo.

No caso das duas questões selecionadas para este estudo, buscou-se, em decorrência do objetivo do atlas, demonstrar como se configuram as trocas sociodialetais entre informantes autóctones e alóctones. Acredita-se que esse campo semântico, "Frutas e

\footnotetext{
${ }^{1}$ Utilizaram-se, no momento da entrevista, fotos dos referentes para facilitar a elicitação da resposta.
} 
Atividades Agropastoris", possa fornecer indícios para compreender se as variantes recolhidas estão em processo de covariação entre formas locais ou se elas se excluem mutuamente, a depender do grupo de informantes.

\section{Discussão dos resultados obtidos mediante a análise das variantes lexicais}

Procedendo-se ao levantamento das respostas obtidas para a questão 025 do QSL: "Como se chama a fruta que tem a casca verde, cheia de gominhos...", verificou-se que as duas variantes mais citadas, em um universo de 146 respostas, foram, em ordem decrescente, ata e pinha. A primeira obteve os seguintes índices entre os dois conjuntos de falantes: Grupo I - topoestáticos - 60\%; Grupo II - topodinâmicos: 44\%. Pinha, por sua vez, apresenta os seguintes índices: Grupo I: $25 \%$, Grupo II: $35 \% .^{2}$

Dessa forma, nota-se que, em ambos os grupos, predomina a variante $a t a$, mas com maior propensão na fala dos topoestáticos. Pinha, por sua vez, é a segunda variante registrada em números gerais e pode estar mais ligada à fala dos informantes oriundos de migração, apesar de pertencer, também, ao vocabulário ativo dos autóctones.

Cascudo (2012) descreve a fruta anonácea como proveniente das Antilhas e da América Central. Segundo o folclorista, a forma ata procede de Moçambique e sua designação é mexicana. Nesse mesmo verbete, Cascudo faz menção ao nome pinha que, segundo o autor, é utilizado em Angola. O dicionarista estabelece a comparação entre ata e pinha: registra que a primeira denominação é característica do Norte do Brasil, enquanto pinha é falada no Sul do país (CASCUDO, 2012, p. 632-633).

Em termos diatópicos, as duas formas sinalizam áreas específicas, conforme se verifica no cartograma da Figura 2 com distribuição para os dois agrupamentos de informantes. As esferas à esquerda em cada um dos doze pontos de inquéritos representam os informantes sem mobilidade geográfica (topoestáticos), enquanto à direita localizam-se os topodinâmicos.

Figura 2: Cartograma diatópico para as variantes ata e pinha - por recorte de mobilidade geográfica do informante

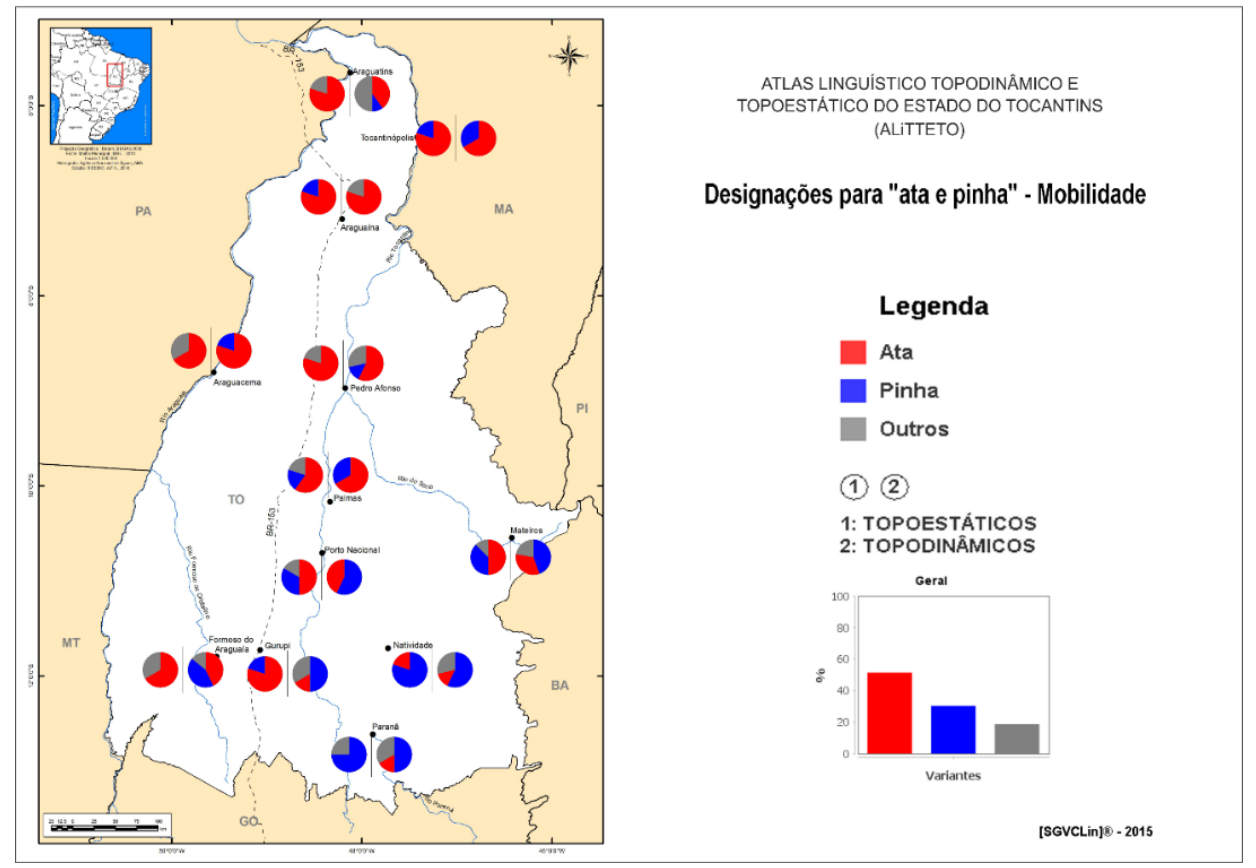

\footnotetext{
${ }^{2}$ Os topoestáticos são responsáveis por 65 respostas, enquanto os topodinâmicos por 81 .
} 
Fonte: ALiTTETO (2018)

Os dados da carta referente à Figura 02 mostram o predomínio de ata nos seis pontos mais setentrionais, localizados acima de Porto Nacional: Palmas, Pedro Afonso, Araguacema, Araguaína, Tocantinópolis e Araguatins, independentemente de se tratar de falantes autóctones ou alóctones. Acredita-se que essa distribuição aponte para a predominância de uma variante nortista. A diferença começa a se esboçar ao sul de Porto Nacional à esquerda do esquema (em cor vermelha), ou seja, nos informantes sem mobilidade geográfica, enquanto pinha centra-se principalmente à direita (em cor azul). No entanto, ao analisar o cartograma, evidencia-se que, mesmo havendo essa diferenciação entre as preferências lexicais de informantes com trajetórias demográficas distintas, as duas variantes: ata e pinha demarcam áreas dialetais específicas: pinha concentra-se no Sudeste, com irradiação para as localidades mais centrais, enquanto ata circunscreve-se ao Sudoeste, Centro e Norte do Tocantins.

O Sudeste tocantinense, historicamente, abriga as localidades mais antigas, que funcionaram, nos primórdios do território, como importantes núcleos vinculados às atividades mineratórias, tais como Porto Nacional, Natividade e Paranã. Essas localidades já possuíram alta densidade demográfica, mas, recentemente, têm perdido parte de sua população mais jovem para outras microrregiões, tornando-se um espaço em que predominam habitantes mais idosos.

Situação interessante verifica-se na questão 028 - Designações para ponta roxa do cacho da bananeira, que coletou o total de nove formas distintas, por ordem produtiva: mangará, umbigo, coração, buzo, flor (da bananeira), fio, pendão, olho e figa. Nesta análise, discorre-se apenas sobre as quatro primeiras: mangará, umbigo, coração e buzo.

Nos dois grupos de informantes predomina mangará, com maior percentual de citação pelos topodinâmicos - 37\%, contra $30 \%$ dos topoestáticos, com distribuição areal por todo o espaço tocantinense, à exceção da porção lateral Sudeste - Natividade e Paranã.

A variante é apresentada por Houaiss (2009) como procedente do Nordeste brasileiro, com datação de 1584 . Nesse caso, a predominância de mangará pode indicar que essa denominação adentrou o Tocantins via migrantes nordestinos e se firmou como variante preferencial, inclusive pelos autóctones. A Figura 3 mostra a distribuição espacial e social das variantes mais produtivas.

Figura 3: Cartograma diatópico para as variantes mangará, coração, umbigo e buzo - por recorte de mobilidade do informante

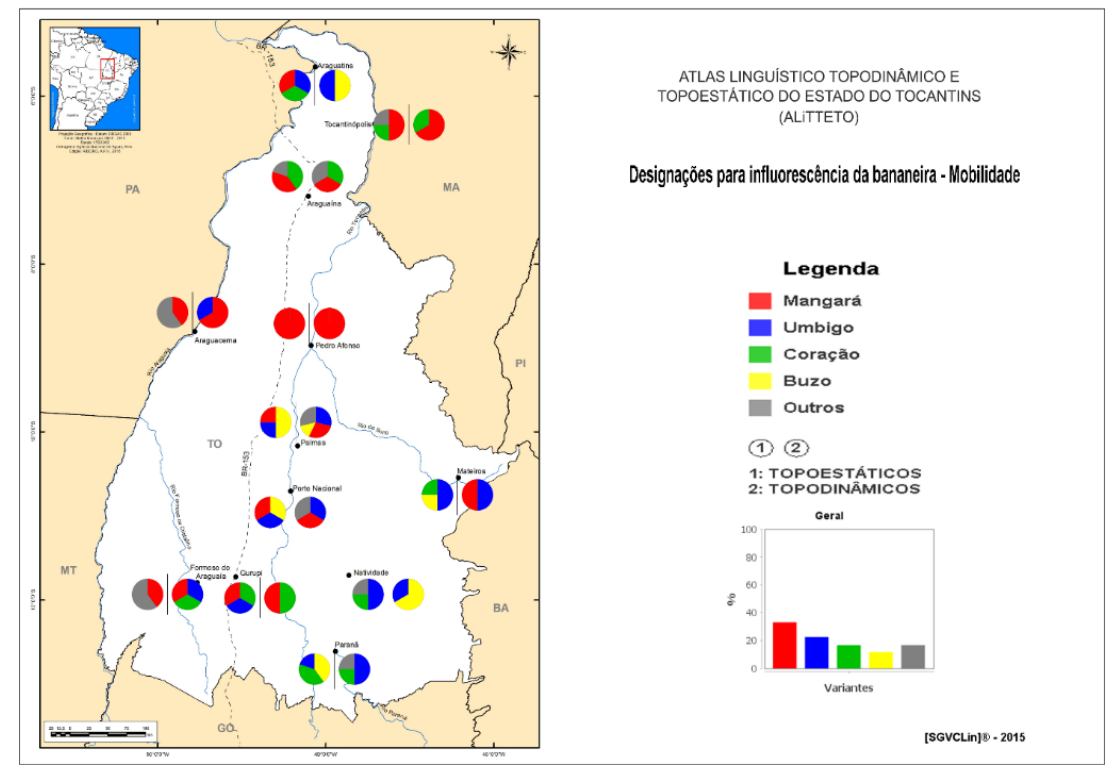

Fonte: ALiTTETO (2018) 
A distribuição das variantes obtidas mediante a pergunta 028 do QSL é mais complexa do que a observada na Figura 1, devido ao intenso polimorfismo registrado, traduzindo uma instabilidade entre as diversas variantes que só o tempo irá direcionar para a manutenção de uma das formas ou a coexistência dessa pluralidade.

Em dois pontos extremos na porção setentrional (Tocantinópolis e Araguaína) registra-se a covariação entre mangará e coração em ambos os grupos. Em Araguatins, porém, a concorrência entre essas duas variantes foi registrada apenas no Grupo 1 e umbigo e buzo ocorrem proporcionalmente, no Grupo 2. Caminhando para o sul, Pedro Afonso foge à regra com a predominância absoluta de mangará entre os falantes de ambos os grupos. $\mathrm{Na}$ capital Palmas, no entanto, enquanto buzo é mais frequente entre os autóctones, verifica-se aí uma disputa entre mangará e umbigo em ambos os grupos. Entre os alóctones verifica-se a alternância entre mangará, umbigo e buzo.

Olhando para as variantes registradas nas seis localidades mais meridionais, observase, novamente, um significativo polimorfismo, com distribuição irregular das quatro variantes mais produtivas pelos Grupos I e II, sem que se possa afirmar qual variante é a local, qual é a exógena.

É certo que, numa visão geral, em Tocantins, registra-se uma tendência maior para mangará, que ocorre com frequência variável em dez dos doze pontos, não tendo sido citada pelos autóctones apenas em Mateiros, Natividade e Paranã, mas concorrendo com umbigo em Mateiros junto aos informantes do Grupo II.

A segunda variante mais citada, umbigo, por sua vez, está presente em nove dos doze pontos, concentrando-se na porção mais ao sul, sobretudo no Grupo I em Mateiros e Natividade e no Grupo II, em Paranã. Apresenta-se com a seguinte distribuição por grupo de informante: Grupo I: $19,15 \%$ e Grupo II: 26,32\%, indicando tratar-se de variante, possivelmente, procedente de outras regiões brasileiras, devido à ligeira preferência dos informantes móveis pela forma umbigo. Em termos diatópicos, esta variante ocorre em quase todo o Tocantins, com exceção da lateral nordeste. Está agrupado em posição oposta à mangará e é mais frequente nas cidades de Natividade e de Paranã (sudeste).

Quanto a coração, presente em oito das doze localidades investigadas, também não apresenta uma distribuição regular, ocorrendo tanto nos pontos mais extremos ao norte (Araguatins, Tocantinópolis e Araguaína), como nos do sul (Mateiros, Formoso do Araguaia, Gurupi, Natividade e Paranã), sem que haja preferência específica entre os falantes dos dois grupos, a não ser em Gurupi com frequência igual à de mangará no Grupo II. No cômputo geral, há uma ligeira preferência da forma coração na fala dos informantes estáticos $19,15 \%$, enquanto nos topodinâmicos esse número chega a 13,16\%. A dicionarização deste item lexical mostra que Houaiss (2009) a inclui como regionalismo do Nordeste e como variante para mangará, com datação de 1584.

A quarta variante mais produtiva, buzo, coletada em metade das localidades investigadas, concentra-se, principalmente, na porção mais ao centro e ao leste, na fala dos autóctones. No Grupo I, concorre com as outras variantes em Porto Nacional, Mateiros e Paranã), embora covarie com umbigo, na fala dos alóctones em Araguatins, no extremo norte e seja a mais produtiva em Natividade.

A descrição de como as variantes para a inflorescência da bananeira (QSL 028) se distribuem, areal e socialmente, pelas localidades investigadas em Tocantins, mostra um quadro complexo multivarietal, já observado por Cuba (2000), nos pontos que compõem o espaço denominado por Nascentes como incaracterístico. Isto significa que o papel destinado aos diferentes grupos sociais e econômicos, ao longo do tempo, será determinante para a manutenção ou mudança no léxico tocantinense.

Quanto à fruta descrita na pergunta 025 do QSL, as denominações parecem estar se polarizando para a distribuição de pinha nas localidades do sul e ata nas do norte, embora a 
primeira tenha um alcance maior em todas as localidades. Convém lembrar que, na capital, a variante ata se sobrepõe à pinha tanto entre os falantes topoestáticos como entre os topodinâmicos, o que também pode apontar para a sedimentação da forma considerada de maior prestígio.

\section{COMPARAÇÃO DA OCORRÊNCIA DAS VARIANTES PARA A INFLORESCENCIA DA BANANEIRA REGISTRADAS NO ALITTETO COM OS DADOS DAS CAPITAIS REGISTRADOS NO ATLAS LINGUÍSTICO DO BRASIL (CARDOSO ET AL, 2014, VOL. 2)}

Antes de proceder à comparação dos dados, convém esclarecer que Palmas não foi incluída na rede de pontos do ALiB por se tratar de capital muito jovem, fundada em 1989, onde não se encontrariam informantes da $2^{\mathrm{a}}$ faixa etária naturais da localidade (de 50 a 65 anos). No entanto, para o interior foram inseridas as localidades de Pedro Afonso (023) e Natividade (024).

No Atlas Linguístico do Brasil (ALiB), a carta L07 sobre a inflorescência terminal da bananeira mostra, com os dados das capitais, que a variante mangará ocorre, na Região Norte, em cinco das seis capitais pesquisadas, sendo exclusiva em Manaus e Boa Vista; majoritária em Rio Branco e Porto Velho; concorre, com outras variantes, em Macapá. Na Região Nordeste, dentre as nove capitais, mangará foi registrada como exclusiva em João Pessoa; majoritária em Natal e Fortaleza e covariando com outras formas em São Luís e Recife. As capitais das demais regiões não registraram essa variante.

Brasil (1997) e Simielli (2006) afirmam que as correntes migratórias mais numerosas dirigidas ao Tocantins, nas três últimas décadas do século $\mathrm{XX}$, procederam do Nordeste (sobretudo Maranhão, João Pessoa e Bahia), seguidas pelas outras regiões, como Pará (N), Goiás (CO) e Minas Gerais (SE). Assim, pelo que demonstram os dados coletados pelo ALiTTETO, no que se refere à mangará, a distribuição dessa variante comprova parte dessa influência. Os dados do ALiB referentes ao interior, ainda em estudos, poderão mostrar com maior clareza a influência dessas correntes migratórias.

A segunda forma mais frequente em Tocantins, umbigo, foi registrada no ALiB (CARDOSO et al., 2014, vol. 2, p. 173), com exclusividade em Belém (N) e Belo Horizonte (SE); majoritária nas capitais do Centro Oeste e em Vitória (SE) e covariando em Macapá (N), São Luís e Salvador (NE). Os dados apontam para a influência dessas localidades sobre o Tocantins, já reportadas por Brasil (1989) e por Simielli (2006).

No ALiB (CARDOSO et al., 2014, vol. 2, p. 173), coração é majoritária apenas em Curitiba (S), concorrendo com outras variantes em São Paulo (SE) e Porto Alegre (S) e com menor representatividade em Aracaju e Salvador (NE), Cuiabá e Goiânia (CO) e Florianópolis (S). Por se tratar de forma mais frequente no espaço destinado ao Falar do Sul (Nascentes, 1958), é possível que correntes migratórias mais recentes tenham exercido essa influência sobre o falar tocantinense, que parte desse território Nascentes (1958) colocou no grupo do Falar do Norte (subfalares nortista, nordestino e baiano), e parte no território incaracterístico, além do subfalar sulista.

Quanto a buzo, não foi cartografada pelo ALiB aparecendo apenas no grupo de outras, devido ao baixo número de ocorrências, em Maceió, Aracaju e Salvador. No Tocantins, pela distribuição areal e social (mais frequente na fala dos informantes topoestáticos), presume-se que se trate de variante local, mais conservadora.

Em termos gerais, a partir da análise das quatro variantes para inflorescência da bananeira, verifica-se uma relação de coexistência entre formas mais ou menos locais, havendo entre os dois grupos de informantes a citação e o uso de todas as formas lexicais elencadas. A dificuldade de traçar isoléxicas, demarcando o emprego de variantes específicas, 
indica que os informantes topodinâmicos e topoestáticos realizam trocas sociodialetais sem que haja qualquer estigma em relação à fala de um ou de outro grupo.

\section{CONSIDERAÇÕES FINAIS}

O presente artigo abordou as trocas sociodialetais no estado do Tocantins, espaço este marcado por intensas migrações intra e interestaduais. Para esse fim, analisaram-se as variantes oriundas de duas questões presentes no campo semântico "Frutas e Atividades Agropastoris".

Sobre a pergunta inicial "Se identificadas as modalidades dialetais, oriundas dos dois diferentes grupos, topoestáticos e topodinâmicos, quais relações elas exercem: covariação ou se excluem mutuamente?", nota-se que o corpus não demonstrou aparente disparidade entre as variantes analisadas em ambos os grupos: migrantes e não migrantes, o que pode ser explicado pelo fato de o Tocantins possuir formação histórica e social sempre vinculada a grupos porcedentes de vários territórios. Nesse caso, as variantes analisadas demonstram processo de covariação entre os dois tipos de informantes, sem aparente rejeição das modalidades faladas pelos topoestáticos em contraste com os topodinâmicos.

Acredita-se, por isso, que haja, entre os falantes autóctones, diante dos grupos demograficamente móveis, uma reafirmação das formas locais. Da mesma forma, é possível que os migrantes adotem atitudes positivas diante das diferenças linguísticas do novo habitat, mas sem abandonar as formas de seu dialeto.

\section{Referências}

ALTENHOFEN, Cléo Vilson. Migrações e contatos linguísticos na perspectiva da Geolinguística Pluridimensional e Contatual. Revista de Letras Norteamentos. Estudos Linguísticos, Sinop, v. 6, n. 12, p. 31-52, jul./dez. 2013. Disponível em: http://sinop.unemat.br/projetos/revista/index.php/norteamentos/article/view/1216 . Acesso em agosto de 2016.

ALTENHOFEN, Cléo Vilson; THUN, Harald. "As migrações e os contatos linguísticos na Geografia Linguística do Sul do Brasil e Bacia do Prata". In: AGUILERA, Vanderci de Andrade; ROMANO, Valter Pereira (Orgs.). A geolinguística no Brasil: caminhos percorridos, horizontes alcançados. Londrina: Eduel, 2016, p. 371-392.

BRASIL, Marília Carvalho. Os fluxos migratórios na Região Norte nas décadas de 70 e 80: uma análise exploratória. Cad. Est. Soe. Recife, v. 13, nº 1, p. 61-84, jan/jun, 1997.

CARDOSO, Suzana Alice Marcelino et al. Atlas Linguístico do Brasil: cartas linguísticas 1, vol. 2. Londrina: Eduel, 2014.

CAVALCANTE, Ivana; KIMURA, Simone. "Mapeamento do patrimômio cultural do estado do Tocantins". In: CAVALCANTE, Ivana; KIMURA, Simone (Orgs.). Vivências e sentidos: o patrimônio cultural do Tocantins. Goiânia: Iphan/14 ${ }^{\mathrm{a}}$ Superintendência Regional, 2008, p. 90-159.

CAVALCANTE, Maria do Espírito Santo Rosa. O discurso autonomista do Tocantins. Goiânia: UCG, 2003. 
CUNHA, José Marcos Pinto da; BAENINGER, Rosana (Coords.). Redistribuição da população e meio ambiente: São Paulo e Centro Oeste. Sistematização das Informações Censitárias sobre Migração - Estado de Tocantins. Campinas: Unicamp, Núcleo de Estudos de População, 2000.

HOUAISS, Antônio. Dicionário Houaiss eletrônico. Instituto Antônio Houaiss. Objetiva, 2009.

PENNA, Maura. "Relatos de migrantes: questionando a noção de perda de identidade e desenraizamento". In: SIGNORINI, Inês (Org.) Língua(gem) e identidade: elementos para uma discussão no campo aplicado. Campinas: Mercado das Letras, 2006.

SILVA, Greize Alves da. Atlas Linguístico Topodinâmico e Topoestático do Estado do Tocantins (ALiTTETO). 2018. 2v. Tese (Doutorado em Estudos da Linguagem). Universidade Estadual de Londrina, Londrina, 2018.

SIMIELLI, Maria Elena. Geoatlas. São Paulo: Ática, 2006.

THUN, Harald. La geolingüística como lingüística variacional general (con ejemplos del Atlas lingüístico Diatópico y Diastrático del Uruguay). In: INTERNATIONAL CONGRESS OF ROMANCE LINGUISTICS AND PHILOLOGY (21.: 1995: Palermo). Atti del XXI Congresso Internazionale di Linguistica e Filologia Romanza. (Orgs). Giovanni Ruffino. Tübingen: Niemeyer, 1998. v. 5, p. 701-729.

Greize Alves da Silva greize_silva@yahoo.com.br

Vanderci de Andrade Aguilera vanderci@uel.br

Recebido em: 20/02/2019

Aceito em: 20/04/2019

Publicado em: Junho de 2019 